\title{
IMPROVING THE LEARNING EXPERIENCE OF BUSINESS SUBJECTS IN ENGINEERING STUDIES USING AUTOMATIC SPREADSHEET CORRECTORS
}

\author{
Maria Assumpció Rafart Serra ${ }^{1}$, Andrea Bikfalvi $^{1}{ }^{\mathbb{D}}$, Josep Soler Masó ${ }^{1}$, \\ Ferran Prados Carrasco ${ }^{2}$ iD, Jordi Poch Garcia ${ }^{1}$ iD \\ ${ }^{1}$ Universitat de Girona (Spain) \\ ${ }^{2}$ University College London (United Kingdom) \\ assumpcio.rafart@udg.edu, andrea.bikfalvi@udg.edu, josep.soler@udg.edu, F.PradosCarrasco@,cs.ucl.ac.uk, \\ jordi.poch@udg.edu
}

Received November 2016

Accepted February 2017

\section{Abstract}

The combination of two macro trends, Information and Communication Technologies' (ICT) proliferation and novel approaches in education, has resulted in a series of opportunities with no precedent in terms of content, channels and methods in education. The present contribution aims to describe the experience of using an automatic spreadsheet corrector, its perceived benefits as well as its impact on academic results. A total of 179 students coursing technical studies attended a basic course on business administration in the framework of which the field work was conducted. Perception assessment of students demonstrates a very good opinion about the learning experience using the proposed ICT tool. The user perception evaluation also shows that it is a valuable learning tool, while students who obtain a high final qualification are the ones that have been positively evaluated in the sessions using the automatic spreadsheet corrector. Beyond these highlighted benefits for students, teachers gain time, effort and workload reduction. The validity of the proposal is tested in the Polytechnic School of the University of Girona in Catalonia (Spain).

Keywords - e-Learning, Spreadsheet, Business, Engineering, Higher education, ACME. 


\section{Introduction}

Quality education is one of the seventeen goals of the United Nations aiming towards sustainable development (UN, 2016). While education has long been on the global institutional agenda, the field of practice has advanced under the influence of two major macro trends, namely Information and Communication Technologies' (ICT) proliferation and novel approaches in education. The myriad of opportunities positioning at this intersection of the two has gradually induced changes at all levels of education.

Higher education is relevant since it is the major workforce provider of the future, by preparing students for the world of work. Competences are the proven ability to use knowledge, skills and personal, social and/or methodological abilities, in work or study situations and in professional and personal development (ESCO, 2016). Competences are important while they represent a way of sustainable education taking into about at least two aspects: employer required competences (versus academia provided ones) and the availability of knowledge and its increasing velocity of caducity (versus competence durability).

It is in this panorama that the European Commission affirms that fostering competences is the object of all educational programmes. The ICT competence is one of the most universal and generating less controversy in terms of importance. Its evolution is highly marked of its beginning, mastery of operation and usage of computers, to its current conceptual stage of understanding as the mastering of software applications (text processing, presentation, spreadsheet and Internet). Nowadays, it is not a matter of "if" but a matter of "how" education -at all levels- can contribute to its acquiring or improvement. Complementary to the ICT competence, basic business knowledge and skills are mandatory from the perspective according to which students will be employed and should understand the functioning of organizations they opt to serve. This competence is implicit in economics and business studies, but it has relatively recently been added to other studies' curricula, in general, and engineering in particular.

The competence of business administration is fundamental for future engineers since one of their tasks will be making business more competitive. With this aim in mind it is necessary to have a basic understanding among others of financial analysis, cost analysis, balance sheet interpretation in order to make the most opportune decisions (Gregory, 2008). Improving competitiveness, as highlighted by the European Commission (European Commission, 2010), implies a sustainable growth of the economy based on value added to products and services while creating new employment. It is in this scenario that engineers are expected to deploy a key 
role through innovation and new product and process developments, intra- and entrepreneurship and new business ventures in which mastery of the business competence is a must. Acknowledging this necessity, the training and education system should make sure that the students achieve the knowledge and skills necessary for business creation and management (Momete, 2015). Unfortunately, universities are still too slow -compared to what would be desirable- when having to introduce changes in engineering study plans. Transformation, or more radical, innovation in education is necessary at all organizational levels including management, departments and ultimately teachers involved (Graham, 2012). The changes introduced should train engineers able to combine disciplines -that are each time more specialized (such as robotics, biomedicine, etc.)- with a variety of interdisciplinary knowledge (like business, information systems, etc.) that could further permit a fluid communication with their work environment (Kamp, 2014).

Towards this finality, initiatives in practice have gradually evolved and spread. However, most often they are scattered, very context relative (single university, one subject, etc.), solution specific, impossible or difficult to scale, or they just remain unpublished. Initiatives published in the academic literature have been identified by searching specialized databases, such as Science Direct, Scopus, Dblp, Proquest and Google Scholar, using the terms, synonyms and combinations of "business", "engineering", "spreadsheet" and "automatic corrector". We selected those publications that i) refer to an e-learning environment, and ii) that are related to the automatization of processes that occur in exercise solving by the means of spreadsheets. More concretely, the focus is on those solutions that consider or permit the automatic generation or correction also capable of providing a feed-back and/or a qualification.

Even recognizing individual advantages of existing proposals, most often they are not integrative, a concept understood in a broad interpretation. With the aim of overcoming this gap, the objective of this paper is to present an innovative approach to teach business to students coursing technical studies. More concretely, we aim to present the experience of using an automatic spreadsheet corrector, its perceived benefits as well as its impact on academic results. This objective is part of a wider and more ambitious goal, namely the improvement of the teaching/learning experience, the development of autonomous learning, the deepening of knowledge acquired in academia and the mastering of ICT skills and competences using spreadsheets. Ultimately we aim to contribute to students' preparation to the world of work. The article is constructed and written with the teachers and the students in mind. Our contribution is 
part of a long-lasting experience and in this article we present a partial approach, concretely the one referred to spreadsheets.

\section{Literature review}

Spreadsheets have been introduced in many different teaching settings, indifferently of educational level or subject. Focusing in the field of business administration, spreadsheets and consequently the spreadsheet use competence is very important as stated by (Walters \& Pergola, 2012). Spreadsheets' importance is highlighted in a considerable volume of literature, in general, and its use in business administration, in particular (Ahmed, 2008; Leong \& Cheong, 2008; Mays, 2015). All these works, and other conceptually and thematically similar ones, share a common element. This refers to the experience of using spreadsheets, guided by tutorials or teachers, but with no reference on more advanced modalities of use including automatic correction and/or evaluation.

The integration of the solution developed in a learning management system (LMS), like Moodle, is one of the basic requirements to be fulfilled. It has to permit automatic generation of multiple and unique problem statements permitting the correction of multiple Excel sheets. Students will solve the problem and they will submit the solution for its assessment/correction. The system has to permit a formative assessment, returning an adequate feed-back, as well a summative assessment, assigning a grade or qualification in accordance with the quality of the solution provided.

With this objective in mind we reviewed the panorama of existing initiatives published on the topic of automatic spreadsheet correctors permitting us to affirm the existence of such systems, on one hand, and detecting their characteristics, on the other hand. This operation is useful in order to position our initiative in the context of automatic spreadsheet correctors.

Lehman and Herring (2003) presented a method for designing spreadsheets that enable students to obtain immediate feedback. Blayney and Freeman (2004) developed a system that permits individualized spreadsheet assignments. A further work of the same authors (Blayney \& Freeman, 2008) described an approach that instructors can use to create drill and-practice rules-based questions in Excel that require students to enter cell-referenced formulas, thus promoting greater understanding of underlying concepts. The questions are marked automatically and provide individual feedback to the students. 
The creation of problem statements that contain individualized data sets with the aim that each student can dispose of a unique exercise in order to avoid copies is especially important in courses with high number of participant students. Tsai and Wardell (2006) in their paper described an approach that utilizes Excel macros to help instructors to enhance and assess their students' learning. Kovacic and Green (2012) developed a method to assess and automatically grade students' spreadsheet and database skills. The solution is exclusively oriented to prove the degree to which students have mastery of spreadsheets. This is done by using quizzes. The student answers questions that are marked as solved correctly or incorrectly. Each question has a value and according to the correct responses a final grade is generated. Nnadi and Rosser (2014) proposed a system able to generate individualized accounting questions. The solution is useful in assessing both basic and advanced topics in financial statements analysis, budgeting, cash flow statement, income statement, balance sheet, investment appraisal techniques, costing techniques, etc. Oppositely, it does not correct or evaluate automatically. Basically its value consists in generating individualized problem statements. Bertheussen (2014) presented a financial problemsolving application formed by an Excel workbook composed of four worksheets and two VBA code modules. The teacher creates three differentiated sheets, a solution worksheet, a marking worksheet and a problem worksheet.

Table 1 summarizes the key characteristics we detected in the reviewed articles. Although acknowledging the author's efforts and the steps advanced in the field, it is observable that existing initiatives have some weaknesses. For example, some are only able to correct a single sheet's cells (as compared to multiple sheets), or they are not integrated in a learning management system with all advantages this implies.

\begin{tabular}{|l|c|c|c|c|c|c|}
\cline { 2 - 6 } & $\begin{array}{c}\text { Integrated } \\
\text { in LMS } \\
\text { (Moodle) }\end{array}$ & $\begin{array}{c}\text { Personalized } \\
\text { exercises }\end{array}$ & $\begin{array}{c}\text { Correction } \\
\text { of multiple } \\
\text { Excel files }\end{array}$ & $\begin{array}{c}\text { Formative } \\
\text { evaluation } \\
\text { (feed-back) }\end{array}$ & $\begin{array}{c}\text { Summative } \\
\text { evaluation } \\
\text { (automatic } \\
\text { scoring) }\end{array}$ & $\begin{array}{c}\text { Specific for } \\
\text { Business } \\
\text { Administration / } \\
\text { Accounting }\end{array}$ \\
\hline $\begin{array}{l}\text { Lehman \& } \\
\text { Herring, 2003 }\end{array}$ & $\mathbf{x}$ & $\mathbf{x}$ & $\mathbf{x}$ & $\mathbf{x}$ & $\checkmark$ \\
\hline $\begin{array}{l}\text { Tsai \& Wardell, } \\
\text { 2006 }\end{array}$ & $\mathbf{x}$ & $\checkmark$ & $\mathbf{x}$ & $\checkmark$ & $\mathbf{x}$ & $\checkmark$ \\
\hline $\begin{array}{l}\text { Blayney \& } \\
\text { Freeman, 2008 }\end{array}$ & $\mathbf{x}$ & $\mathbf{x}$ & $\mathbf{x}$ & $\checkmark$ & $\checkmark$ & $\mathbf{x}$ \\
\hline $\begin{array}{l}\text { Kovacic \& Green, } \\
2012\end{array}$ & $\checkmark$ & $\mathbf{x}$ & $\mathbf{x}$ & $\checkmark$ & $\mathbf{x}$ & $\checkmark$ \\
\hline $\begin{array}{l}\text { Nnadi \& Rosser, } \\
2014\end{array}$ & $\mathbf{x}$ & $\checkmark$ & $\checkmark$ & $\checkmark$ & $\checkmark$ \\
\hline Bertheussen, 2014 & $\mathbf{x}$ & $\checkmark$ & $\checkmark$ & $\checkmark$ \\
\hline
\end{tabular}

Note: $\mathbf{x}$ - not a feature of the tool; $\checkmark$-feature of the tool

Table 1. Characteristics of automatic spreadsheet correctors, a literature review 


\section{Methodology}

Our research is a quasi-experimental empirical study. As affirmed by Cohen, Manion and Morrison (2007, pp. 274) "Frequently in learning experiments in classroom settings, the independent variable is a stimulus of some kind, a new method in arithmetical computation for example, and the dependent variable is a response, the time taken to do twenty sums using the new method. Most empirical studies in educational settings, however, are quasi-experimental". In order to fully understand the stimulus, the automatic spreadsheet corrector as a new method introduced in the teaching process, its technical and educational features need further explanation.

\subsection{The technical approach: The automatic corrector of spreadsheets in the ACME platform}

From a technological point of view it is mentionable that the University of Girona (UdG) uses an LMS, more concretely Moodle, which enables managing students, learning materials, teaching/learning activities, etc. Moodle further integrates the ACME platform (Soler, Prados, Poch \& Boada, 2012) a solution specialised in the automatic correction of complex exercises. Taking into account that the ACME platform already disposed of an initial version of spreadsheet corrector (Poch, Prados, Soler \& Boada, 2013) a further and more advanced system was necessary. Its distinctive features compared to the initial version were basically two:

- simplification in the way to create exercises, and

- possibility to automatically correct files with multiple spreadsheets.

The basic idea is that the student connects to the ACME platform accessing the corresponding exercise and obtaining a unique problem statement. Next, the student downloads the spreadsheet that should be used for generating the solution. This template does not contain data or formulas. It just shows the labels that indicate what information is expected and in which cells. All students receive the same instructions. Students autonomously work using the spreadsheet and the teacher is an on demand support in helping to solve the doubts arising while solving the proposed exercises. Once the exercise is apparently solved the student submits it for its automatic correction. The ACME automatic spreadsheet corrector immediately performs the correction and devolves the feed-back corresponding to the incorrect cells. 
The correction is performed by comparing the version sent by the student with the solution version created by the teacher in the moment of generating the problem statement. Not all results cells are compared. The system requires the coincidence of a determined set of cells which further indicate the correctness of the exercise. This way, students have the freedom to configure their own spreadsheets with the minimum possible restrictions. The verified cells have a range of correct values -with a certain error margin- assuring, on the one hand, the avoidance of problems generated by rounding, and on the other hand, making sure -by using formulas- the authenticity of the student's spreadsheet.

\subsection{The teaching approach: integrating spreadsheets in business subjects}

Spreadsheets have an extended use in organisations and enterprises and it is advisable that students have knowledge and skills in their practical application. Creating templates for solving problems is a time and effort consuming matter and it requires thinking about information required by the system, ways to systematise problem resolution, creating algorithms, relating calculations, envisioning manners to visually represent results (tables, charts, values, comments and feed-back according to the results). All in all, it is equivalent with thinking about what information should be obtained and how to obtain it. However, once the template is created, modifying the input data an immediate solution of the problem is obtained which further permits the student the observation of various scenarios in a short time.

The basic subjects of business administration, one of the mandatory non-technical subject students must roll in when coursing technical studies, follow a similar methodology. Content is provided and practiced in three differentiated settings: theory (T), assisted practice (AP) and computer assisted practice (CAP). More concretely, theoretical content that is relevant in the field of business is explained by the teacher. This is followed by practical exercises addressed during AP and applications with spreadsheets contribute in CAP sessions to practice and assimilate contents. The later have the objective to reinforce the contents worked in T and AP sessions, as well as to show the utility of spreadsheets for these purposes.

Every two weeks students have a computer assisted practice class. During the course students participate and work with spreadsheets in the framework of 6 sessions of 2 hours duration of the session, in PC rooms and in the presence of the teacher who provides de minimum, but necessary information to reach the objectives of the sessions. These sessions are aimed as an 
evaluation of students' progress and specific knowledge acquiring and consolidation. Regularly, the activity is contemplated as a continuous evaluation exercise. The exercises proposed to solve with the help of spreadsheets refer to traditional topics in Business Administration, namely

- Balance Sheet,

- Profit and Loss Account,

- Lineal Depreciation,

- Accelerated Depreciation

- Inventory valuation,

- Costs and Breakeven point.

CAP sessions represent the $25 \%$ of the final grade.

During the next two weeks students are free to solve the proposed exercise. Practice periods are sufficiently long and previous to the examination, in order to assure flexibility and selfmanagement. Beyond content, students have the chance to practice a series of competences such as time and task management, responsibility, autonomy, among others. Our experience and practice, however, demonstrates that the majority proceeds with the exercise resolution in the hours previous to the deadline.

The main features of the tool are summarized in Table 2 .

\begin{tabular}{|c|c|c|c|}
\hline & Characteristi & & Explanation \\
\hline \multirow{4}{*}{ Student } & \multirow{4}{*}{ Study tool } & $\begin{array}{l}\text { Each student has a different problem } \\
\text { statement }\end{array}$ & There are no identical exercises \\
\hline & & Identifies erroneous cell & $\begin{array}{l}\text { In the case of committing errors, erroneous } \\
\text { sections/cells are identified }\end{array}$ \\
\hline & & Immediate feed-back & $\begin{array}{l}\text { Students are aware in real time about the } \\
\text { correctness of their solution }\end{array}$ \\
\hline & & Time flexibility & $\begin{array}{l}\text { It permits establishing time frames that facilitate } \\
\text { access to any student at any time }\end{array}$ \\
\hline \multirow{5}{*}{ Teacher } & \multirow{5}{*}{$\begin{array}{l}\text { Assessment } \\
\text { tool }\end{array}$} & Generate different problem statement & $\begin{array}{l}\text { In voluminous groups generating different } \\
\text { problem statements is highly recommended }\end{array}$ \\
\hline & & Automatic correction & $\begin{array}{l}\text { In voluminous groups automatic correction is } \\
\text { highly valued }\end{array}$ \\
\hline & & Construct groups & Students can be divided into groups \\
\hline & & Add comment to evaluation & $\begin{array}{l}\text { Interaction with students through feed-back } \\
\text { messages is possible }\end{array}$ \\
\hline & & Follow-up & $\begin{array}{l}\text { It is possible to realize follow-ups by activities } \\
\text { and/or student/s }\end{array}$ \\
\hline
\end{tabular}

Table 2. The automatic spreadsheet corrector's main characteristics 


\subsection{Participants}

Pilot: During the academic course 2013-2014 the use of automatic spreadsheet corrector was initiated in the framework a subject with a limited group. Even ACME already accounted with a certain experience in technical subjects typical in technical careers it was contemplated as a pilot for business administration subjects (Basics of Business Administration). The initially conducted pilot of automatic spreadsheet corrector accounted with two groups of students of 66 and, respectively, 51 participants. The main achievement of this experience was the identification of main difficulties encountered by students as well as a very positive valuation from their side. The pilot was used for learning, but not for evaluating. Based on the students' feed-back possible corrections and improvements were performed in the system.

Experiment: After the pilot, it has been extended to more voluminous groups and other subjects. Having the certainty of technical functionality and a positive perception, the implementation was performed during the course 2015/2016 when 179 students had the chance to use it. Among the three groups of business subjects the full implementation accounted with 67, 57 and 55 participants coursing Architecture, Computer Science and Industrial Engineering. The deployment of the computer assisted practical classes using automatic correction of spreadsheets with ACME flowed with total normality. The system is able to automatically correct and evaluate the work done by the student reducing to minimum the time necessary for the correction and evaluation of exercises.

\section{Results}

Sessions are organized as follows. E1 represents the evaluation corresponding to sessions 1 to 5 (Balance Sheet, Profit and Loss Account, Lineal Depreciation, Accelerated Depreciation, Inventory valuation) and E2 corresponds to the evaluation of the 6th session (Costs and Breakeven point), we correlate CAP grades with the final subject grade, normalised on a scale of 0 to 1 , obtained by the students. At individual level, there is no correlation between E1 or E2 grade and the final grade. However, it is possible to detect a pattern when comparing group means and we analyse their distribution accordingly.

Table 3 presents the summary of the experience highlighting most relevant characteristics and figures. 


\begin{tabular}{|c|c|c|c|c|}
\hline & E1 & \multicolumn{2}{|l|}{ E2 } & Total \\
\hline Types of spreadsheet exercises & 12 & & 1 & 13 \\
\hline Total exercises assigned & 2148 & & 179 & 2327 \\
\hline Total exercises solved & 1669 & & 65 & 1734 \\
\hline$\%$ results $/$ attempts & $93 \%$ & & $46 \%$ & $90 \%$ \\
\hline Spreadsheet contribution to CAP & $30 \%$ & & $70 \%$ & $25 \%$ \\
\hline Final grade & \multicolumn{2}{|c|}{ Number of students } & & $\%$ students \\
\hline Absent & & 17 & & $9 \%$ \\
\hline Failed $(0-4,9)$ & & 30 & & $17 \%$ \\
\hline Pass $(5-6,9)$ & & 86 & & $48 \%$ \\
\hline Remarkable $(7-8,9)$ & & 44 & & $25 \%$ \\
\hline Outstanding $(9-10)$ & & 2 & & $1 \%$ \\
\hline Total students & & 179 & & $100 \%$ \\
\hline
\end{tabular}

Table 3. The automatic spreadsheet corrector experience in figures- activities and qualifications

Willing to quantify and document the experience, a perception evaluation questionnaire was distributed in order to collect students' opinion - voluntarily and anonymously- on their experience as users of the ACME platform automatic spreadsheet corrector. As in the case of any innovation, subjective perception evaluation is a good indicator for further potential of improvement, implementation and use. The questions referred to two differentiated aspects: the ICT tool and the learning experience.

Figure 1 presents the results obtained in reference to the tool showing the degree of agreement with regard to the requested aspects. The best ranked option is the teacher's willingness to solve technical problems of the corrector, a result explained by the natural disposition of the trainer to avoid or to solve these while students encounter them especially since this is a new tool generating plenty of doubts. Another very positively perceived feature is that the tool is valuable while providing feed-back on the correctness of calculations. Oppositely, and with the lowest level of agreement, we find the clarity of error messages. This is not a surprising result, while the automatic spreadsheet corrector purposefully only highlights the wrong calculation/result. Students would expect either the steps to reach the correct solution or a further hints on what has been erroneously calculated.

Another aim corresponds to capturing students' opinion on the different learning exercises using automatic spreadsheet correctors. Figure 2 shows the results obtained. Out of the proposed exercises the balance sheet corrected is the most positively evaluated. This is the easiest to solve and that has been solved by most students. Contrary, chronologically the last performed exercise is the one receiving lowest evaluation. It is the most complex one, along with the lowest level of guidance, and that less students solve. 


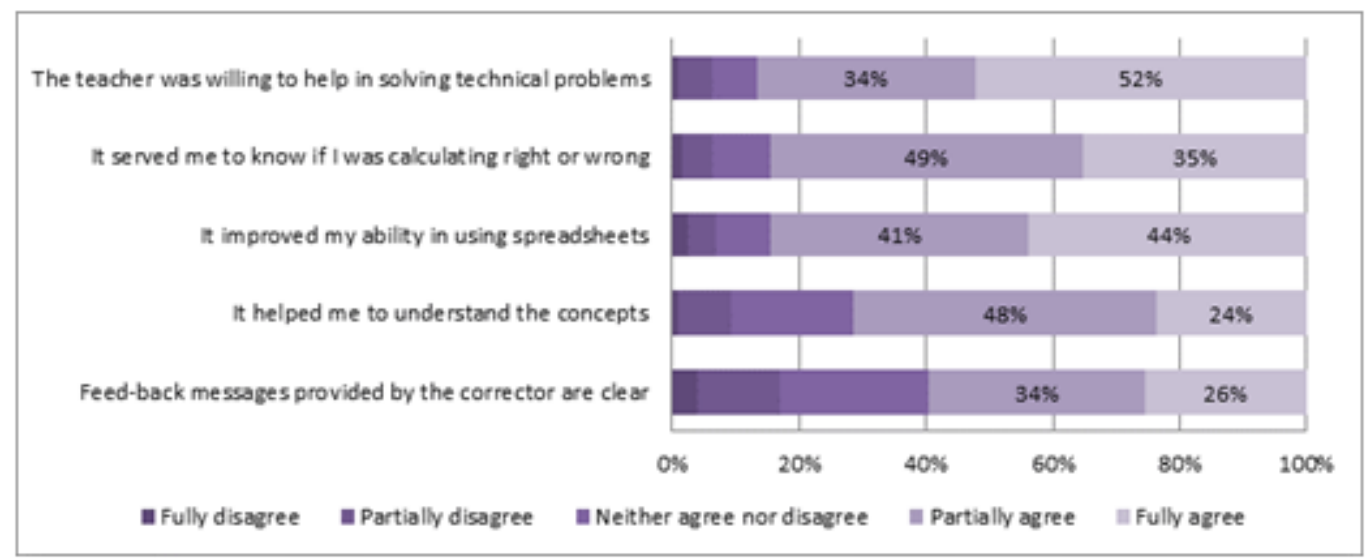

Figure 1. Perception of the automatic spreadsheet corrector experience

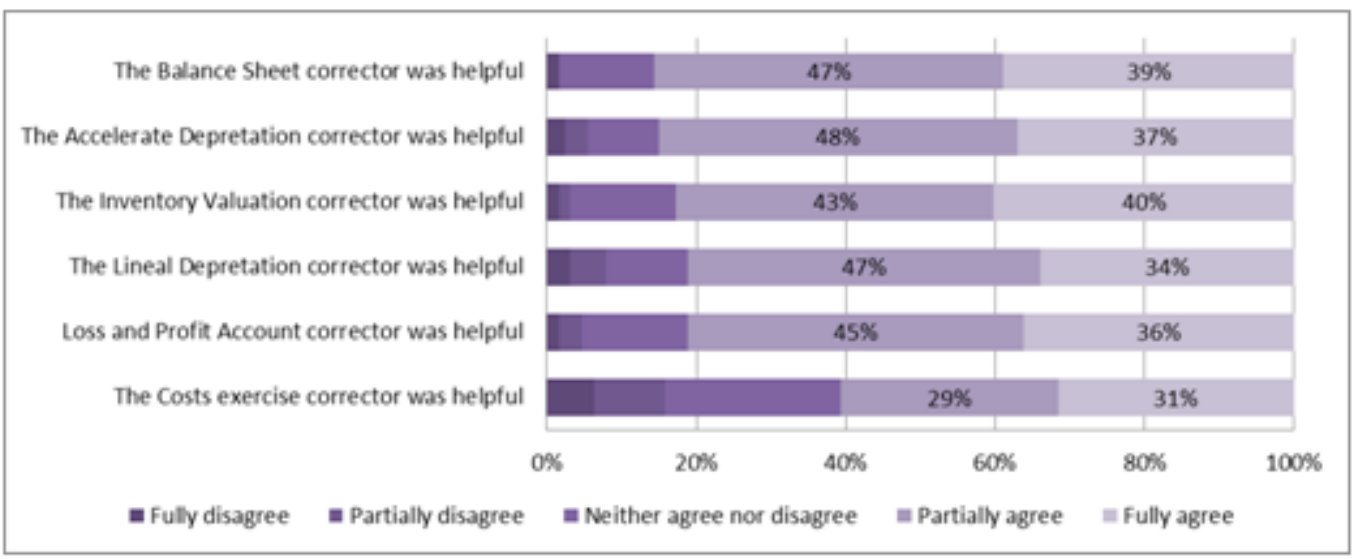

Figure 2. Perception of CAP with the automatic spreadsheet corrector by exercise

Another very important issue of interest is evaluating the effect of CAPs on the final grade. We compute 4 groups according to grade E1 (0-0.25, 0.25-0.5, 0.5-0.75, 0.75-1) and compare the means of their final grade (see Figure 3). The ANOVA test and the data in Table 4 show that there are statistically significant differences between the groups. As a result of a t-test the calculation reveals a statistically significant difference between Group 4 and the other groups with a level of significance of $95 \%$ ( $p$-value $<0.05)$.

The same figure reflects the box-plot of each group jointly with the mean and its interval of confidence. According to data in Figure 3 (a) it appears that $75 \%$ of the students in Group 1 have a final grade below 0.5 while $75 \%$ of the students in the other three groups have a final grade superior to 0.5. Complementarily, if the grouping is done by the final grade (see Figure 3(b)) there are no observable differences between Group 1 and Group 2. However, differences 
are perceivable between these and the other two groups. Some of the appreciations regard: the higher the final grade the better is the E1 result, while it is not vital to have a high E1 grade, and the majority of students who have a final grade below 0.5 (Group 1 and 2) also have a low E1 grade.

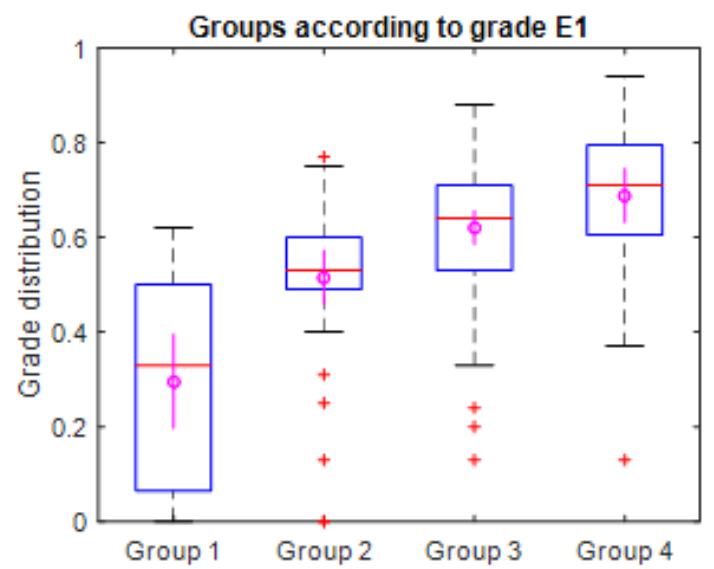

(a)

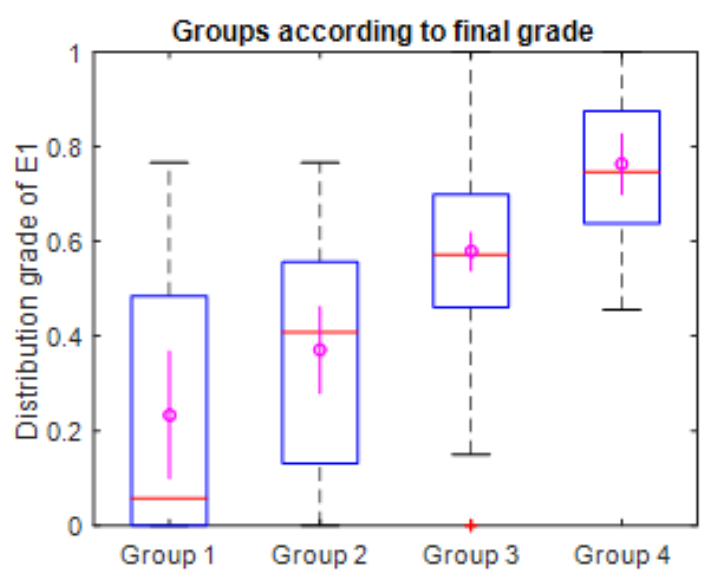

(b)

Figure 3. Comparison between E1 and final grade by grouping data

\begin{tabular}{|c|c|c|c|c|c|c|c|c|c|c|c|c|c|}
\hline \multicolumn{14}{|c|}{ E1 } \\
\hline \multicolumn{8}{|c|}{ Groups according to grade E1 } & & & & & & \\
\hline & & & & & st for equal & means (p-va & ue) & & & & & & \\
\hline & $\mathrm{m}$ & std & & G1 & G2 & G3 & G4 & \multicolumn{6}{|c|}{ Anova } \\
\hline G1 & 0.296 & 0.229 & G1 & & $3.17 \mathrm{E}-04 *$ & 6.48E-07* & $2.26 \mathrm{E}-08 *$ & Source & SS & $\mathrm{df}$ & MS & $\mathrm{F}$ & Prob $>$ F \\
\hline G2 & 0.516 & 0.176 & G2 & & & $2.22 \mathrm{E}-03 *$ & $4.06 \mathrm{E}-05^{*}$ & Groups & 2.471 & 3 & 0.824 & 28.589 & 7.71E-15* \\
\hline G3 & 0.621 & 0.145 & G3 & & & & 4.49E-02* & Error & 4.581 & 159 & 0.029 & & \\
\hline G4 & 0.688 & 0.160 & G4 & & & & & Total & 7.052 & 162 & & & \\
\hline \multicolumn{8}{|c|}{ Groups according to final grade } & & & & & & \\
\hline & & & \multicolumn{5}{|c|}{ Test for equal means ( $\mathrm{p}$-value) } & & & & & & \\
\hline & $\mathrm{m}$ & std & & G1 & G2 & G3 & G4 & \multicolumn{6}{|c|}{ Anova } \\
\hline G1 & 0.224 & 0.281 & G1 & & $7.54 \mathrm{E}-02$ & $5.16 \mathrm{E}-05^{*}$ & $1.16 \mathrm{E}-07 *$ & Source & SS & df & MS & $\mathrm{F}$ & Prob $>F$ \\
\hline G2 & 0.371 & 0.236 & G2 & & & $1.45 \mathrm{E}-04 *$ & $3.76 \mathrm{E}-09 *$ & Groups & 3.913 & 3 & 1.304 & 29.308 & $3.87 \mathrm{E}-15^{*}$ \\
\hline G3 & 0.577 & 0.201 & G3 & & & & $9.34 \mathrm{E}-06 *$ & Error & 7.076 & 159 & 0.045 & & \\
\hline G4 & 0.763 & 0.152 & G4 & & & & & Total & 10.989 & 162 & & & \\
\hline
\end{tabular}

Table 4. Descriptive features of variable E1

The same argumentation and operation is replicated for the evaluation E2 (see Table 5 for detailed descriptive statistics). When grouping by E2 and representing the box plot with the 
group means and their corresponding interval of confidence, the information in Figure 4 (a) shows that there are no statistically significant differences between Group 2 and Group 3, while statistically significant differences are observable between Group 1 and Group 4. It is also visible that $75 \%$ or more of the students in Group 2, 3 and 4 have a final grade hat exceeds 0.5 while only $50 \%$ of students in Group 1 have a final grade above 0.5 . If groups are computed according to the final grade (see Figure 4 (b)) we observe no statistically significant differences between means in Group 1 and 2 and the opposite for Group 3 and 4. All students in Groups 1 and 2 who obtain a final grade below 0.5 mainly have a low or very low E2 qualification, while those who have a high final grade (Group 4) also have a high E2 qualification. Regarding Group 3 shows that for obtaining a final grade exceeding 0.5 there is no need to have an E2 qualification higher than 0.5 .

Summarizing, these results show that in both cases (E1 and E2) in order to obtain a high final grade (superior to 0.75) a high grade for E1 and E2 is necessary and the other way around, those students who obtain a high final grade also have high E1 and E2 grades. Most students who have a low (below 0.25) grade of E1 and E2 obtain a final grade below 0.5. Consequently, it can be affirmed that in general those students who fail to correctly complete the computer assisted practice exercises do not pass the subject and those who have the highest final qualification are those who do best the computer assisted practice exercises.

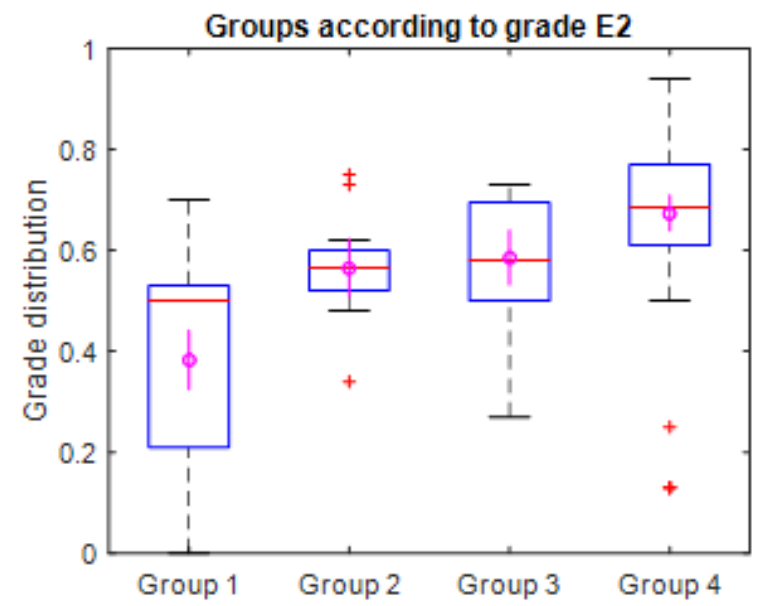

(a)

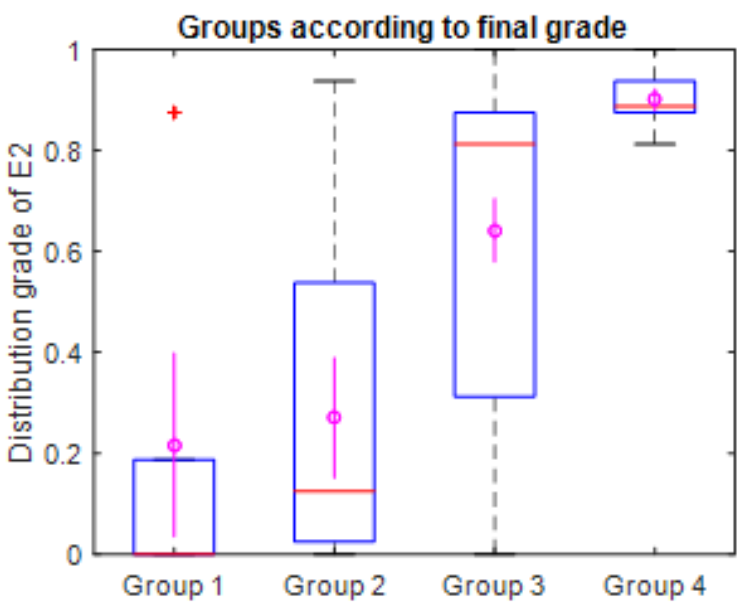

(b)

Figure 4. Comparison between E2 and final grade by grouping data 


\begin{tabular}{|c|c|c|c|c|c|c|c|c|c|c|c|c|c|}
\hline \multicolumn{14}{|c|}{ E2 } \\
\hline \multicolumn{8}{|c|}{ Groups according to grade E2 } & & & & & & \\
\hline & & & & & st for equal & means $(\mathrm{p}$-va & lue) & & & & & & \\
\hline & $\mathrm{m}$ & std & & G1 & G2 & G3 & G4 & \multicolumn{6}{|c|}{ Anova } \\
\hline G1 & 0.383 & 0.208 & G1 & & $3.56 \mathrm{E}-05^{*}$ & $2.36 \mathrm{E}-06^{*}$ & 4.09E-13* & Source & $\mathrm{SS}$ & df & MS & $\mathrm{F}$ & Prob $>F$ \\
\hline G2 & 0.565 & 0.101 & G2 & & & $5.78 \mathrm{E}-01$ & $2.28 \mathrm{E}-03^{*}$ & Groups & 2.623 & 3 & 0.874 & 31.396 & $5.39 \mathrm{E}-16^{*}$ \\
\hline G3 & 0.586 & 0.116 & G3 & & & & $7.68 \mathrm{E}-03 *$ & Error & 4.428 & 159 & 0.028 & & \\
\hline G4 & 0.674 & 0.156 & G4 & & & & & Total & 7.052 & 162 & & & \\
\hline \multicolumn{8}{|c|}{ Groups according to final grade } & & & & & & \\
\hline & & & \multicolumn{5}{|c|}{ Test for equal means ( $\mathrm{p}$-value) } & & & & & & \\
\hline & $\mathrm{m}$ & std & & G1 & G2 & G3 & G4 & \multicolumn{6}{|c|}{ Anova } \\
\hline G1 & 0.201 & 0.378 & G1 & & $5.40 \mathrm{E}-01$ & $1.29 \mathrm{E}-04 *$ & $4.40 \mathrm{E}-07 *$ & Source & SS & $\mathrm{df}$ & MS & $\mathrm{F}$ & Prob $>F$ \\
\hline G2 & 0.267 & 0.310 & G2 & & & 1.19E-06* & $1.76 \mathrm{E}-11 *$ & Groups & 8.107 & 3 & 2.702 & 31.582 & $4.54 \mathrm{E}-16^{*}$ \\
\hline G3 & 0.642 & 0.304 & G3 & & & & $4.41 \mathrm{E}-12^{*}$ & Error & 13.606 & 159 & 0.086 & & \\
\hline G4 & 0.901 & 0.051 & G4 & & & & & Total & 21.713 & 162 & & & \\
\hline
\end{tabular}

Table 5. Descriptive features of variable E2

\section{Discussion and conclusions}

Teaching business subjects to engineering/technical undergraduate students has always been a challenge. It often involves large groups as well as relatively low interest and motivation towards these subjects. Finding creative alternatives to traditional teaching/learning approaches involves ICT and e-learning environments, in general, and the necessity of a practical, action-oriented and problem solving teaching philosophy, in particular.

In this paper we have described an experience based on an automatic spreadsheet correction used in computer assisted practical sessions for teaching basic business subjects to future engineers. A double objective is achieved. First, students have the opportunity to practice basic but relevant notions of business administration. Spreadsheets, in the configuration proposed by the authors, permit the assimilation of deeper notions rather than superficial knowledge of the subject. They permit the "what if?" simulation and interpretation of consequences. Second, students have the occasion to acquire or improve their ICT competence of use of spreadsheets, one of the most used software in business, indifferently of its context. Students participating in the experience reach an intermediate level of competency in using Excel.

The main contribution of the solution elaborated are summarized and listed in Table 4, for both students and educators. We mainly distinguish the tool's contribution in terms of study tool and evaluation tool. The information gathered in the table shows an equilibrium regarding both communities. Even initial preparation of exercises is considerable the ultimate value for effort is also substantial. Another important and relevant aspect is the full integration of the automatic spreadsheet corrector experience with all other existing teaching management ICT solutions 
(intranet, subject design, Moodle, academic records). This further translates into additional facilities especially regarding evaluation.

\begin{tabular}{|l|l|l|l|}
\cline { 3 - 4 } \multicolumn{2}{|l|}{ Contribution } & Explanation \\
\hline \multirow{2}{*}{ Student } & \multirow{2}{*}{ Study tool } & Planning & $\begin{array}{l}\text { As a consequence of flexibility, students can } \\
\text { self-manage the activity }\end{array}$ \\
\cline { 3 - 4 } & Show weaknesses & $\begin{array}{l}\text { It is helpful to identify themes/concepts or } \\
\text { exercises that need further study }\end{array}$ \\
\cline { 3 - 4 } Teacher & $\begin{array}{l}\text { Improve performance } \\
\text { Assessment }\end{array}$ & $\begin{array}{l}\text { It can be observed that practicing increases } \\
\text { performance }\end{array}$ \\
\hline & $\begin{array}{l}\text { Immediate feed-back regarding the } \\
\text { comprehension of a theme/concrete } \\
\text { content }\end{array}$ & $\begin{array}{l}\text { Teachers can observe, by activities, the number } \\
\text { of solutions and degrees of accomplishment }\end{array}$ \\
\cline { 3 - 4 } & Detect and trace study behaviour & $\begin{array}{l}\text { It permits identifying those who read, tried to } \\
\text { solve, solved the exercises, number of intents, } \\
\text { hour of resolution and time trigged to solve }\end{array}$ \\
\hline
\end{tabular}

Table 6. The automatic spreadsheet corrector's contribution to teaching/learning

Inherent to any novel solution, our proposal has some limitations. There is an imbalance between the solution's double facets, tool for learning versus tool for evaluation from the student's perspective. In its current form the feed-back regarding the degree of correctness of the solution is still underdeveloped. The system highlights "correct" and "incorrect" cells. This might generate additional tension to students, since their expectations are often towards more detailed and exact possibilities (guidance for correction, the correct solution, etc.). In this sense the automatic spreadsheet corrector is more a learning tool than an evaluation instrument for the student. Another limitation, and from the teacher's perspective, is that the system is not enough advanced to detect those students who take advantage of other colleague's work. A further limitation is that the experience presented along the present article is deployed in a limited setting, namely the University of Girona (Catalonia, Spain). Although conceptually its extrapolation to other contexts is possible, it has practically not been extended until now. Apparently simple, the imaginary extrapolated solution would have to incorporate an additional sub-system for incident reporting as well as additional efforts would be necessary to a correct integration in other realities (for example, non-Moodle environments).

Some of the mentioned limitations are possible avenues for the future research. Near forthcoming actions include a series of improvements of the system. Having accumulated years of experience in use, one possibility is to classify errors according to predefined categories. Some of these categories refer to calculation error, concept error, to mention just a few. This would further enhance the student's guidance towards reaching a correct solution, but still without 
facilitating it to him/her. Linked to this the alert system will also improve accordingly. An additional feature is being developed currently. It consists in creating a more advanced visualization option in which is able to link the spreadsheet exercises with the notes and contents provided in the theory section. This progress will better situate the student, especially with regard to linking theory and practice. The evaluation feature will also be enhanced. Critical cells for the correct solution will be selected and according to the number of correct cells a numerical value (corresponding to the grade) will be returned. Situating our proposal in the framework of existing solutions (see Table 1) the automatic spreadsheet corrector described in this paper has all the advantages detected in the literature, and which the other solutions cover only partially. Research could also be extended. Some possibilities refer to comparative experiments including generations of students not using the system and current students, or using current students in a control group (no use) and current students using the system. More advanced statistical methods' application could enhance our understanding about the determination relationship between grades. Finally, internationalising the solution would open to opportunity of research possible in a multi-institutional and international panorama.

Against all drawbacks and still possible developments the system remains valid, valuable and beneficial for all the involved. On a general level, both students and teachers improve the learning, respectively, teaching experience. Setting up the system has required long hours and intense dedication. Even implementing improvements require efforts and sometimes frustration. However, all these are compensated with the positive impact both perceived and demonstrated along this manuscript.

\section{Acknowledgments}

The authors are grateful for the financial support from the University of Girona (Spain) MPCUdG2016/024. This work was also supported by the Catalan Government (Grant No. 2014-SGR-1232) and by the Spanish Government (Grant No. TIN2016-75866-C3-3-R).

\section{References}

Ahmed, R. (2008). Spreadsheet software as a teaching and learning tool: perspectives from an undergraduate financial modelling subject. Review of higher education and self learning (RHESL), 1(1), 54-75. https://doi.org/10.2139/ssrn.1101208 
Bertheussen, B.A. (2014). Power to business professors: Automatic grading of problem-solving task in spreadsheet. Journal of Accounting education, 32, 76-87.

https://doi.org/10.1016/j.jaccedu.2014.01.002

Blayney, P., \& Freeman, M.A. (2004). Automated formative feedback and summative assessment using individualized spreadsheet assignments. Australasian Journal of educational Technology, 20(2), 209-231. https://doi.org/10.14742/ajet.1360

Blayney, P., \& Freeman, M.A. (2008). Individualised interactive formative assessments to promote independent learning. Journal of accounting Education, 26(3), 155-165.

https://doi.org/10.1016/j.jaccedu.2008.01.001

ESCO, European classification of skills/competences, qualifications and occupations (2016). Retrieved from: https://ec.europa.eu/esco/portal/escopedia/Competence (Last access date: October 24th, 2016).

European Commission (2010). Europe 2020 - a strategy for Smart, sustainable and inclusive growth, Communication from the Commission.

Cohen, L., Manion, L., \& Morrison, K. (2007). Research Methods in Education. New York: Routledge.

Graham, R. (2012). Achieving excellence in engineering education: The ingredients of successful change. London: The Royal Academy of Engineering.

Gregory, P.J. (2008). Building a financial perspective into an engineering program. 36th Annual Conference European Society for Engineering Education.

Kamp, A. (2014). Engineering education in the rapidly changing world. Rethinking the mission and vision on engineering education at TU Delft. Publication Delft University of Technology.

Kovacic, Z.J., \& Green, J.S. (2012). Automatic grading of spreadsheet and database skills. Journal of information Technology Education. Innovations in practice, 11, 53-70.

Lehman, M.W., \& Herring, C.E. (2003). Creating interactive spreadsheets to provide immediate feedback. Journal of Accounting Education, 21(4), 327-337. https://doi.org/10.1016/j.jaccedu.2003.09.002

Leong, T., \& Cheong, M. (2008). Teaching business modelling using spreadsheets. Informs Transactions on Education, 9(1), 20-34. https://doi.org/10.1287/ited.1080.0015 
Mays, T. (2015). Using spreadsheets to develop applied skills in a business math course: Student feedback and perceived learning. Spreadsheets in Education (eJSiE), 8(3), 1-15.

Momete, D.C. (2015). Joining economic and engineering perspectives - a tool for successful entrepreneurs. Procedia- Social and Behavioral Sciences, 180, 395-400.

https://doi.org/10.1016/j.sbspro.2015.02.135

Nnadi, M., \& Rosser, M. (2014). The individualised accounting questions technique: Using Excel to generate quantitative exercises for large classes with unique individual answers. Accounting Education: an International journal, 23(3), 193-202. https://doi.org/10.1080/09639284.2014.894771

Poch, J., Prados, F., Soler, J., \& Boada, I. (2013). Corrección automática de hojas de cálculo. Congreso Interamericano de Computación Aplicada a la Industria de Procesos.

Soler, J., Prados, F., Poch, J., \& Boada, I. (2012). ACME: An e-learning platform including desirable features for engineering courses. Formación Universitaria, 5(3), 3-16. https://doi.org/10.4067/S0718-50062012000300002

Tsai, W., \& Wardell, D.G. (2006). Creating individualized data sets for student exercises using Microsoft Excel and Visual Basic. Informs Transactions on education, 7(1), 136-148.

https://doi.org/10.1287/ited.7.1.136

UN, United Nations (2016). Sustainable Development Goals. Retrieved from: http://www.un.org/sustainabledevelopment/sustainable-development-goals/ (Last access date: October 24th, 2016).

Walters, L.M., \& Pergola, T.M. (2012). Integrating critical spreadsheet competencies into the accounting curriculum. Journal of instructional pedagogies, 9, 1-25.

\section{Published by OmniaScience (www.omniascience.com) \\ Journal of Technology and Science Education, 2017 (www.jotse.org)}

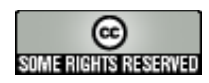

Article's contents are provided on an Attribution-Non Commercial 3.0 Creative commons license. Readers are allowed to copy, distribute and communicate article's contents, provided the author's and JOTSE journal's names are included. It must not be used for commercial purposes. To see the complete licence contents, please visit http://creativecommons.org/licenses/by-nc/3.0/es/ 